\title{
Modeling the connection between selfreported trauma and dissociation in a student sample.
}

Citation for published version (APA):

Merckelbach, H. L. G. J., Horselenberg, R., \& Schmidt, H. G. (2002). Modeling the connection between selfreported trauma and dissociation in a student sample. Personality and Individual Differences, 32(4), 695-705. https://doi.org/10.1016/S0191-8869(01)00070-8

Document status and date:

Published: 01/01/2002

DOI:

10.1016/S0191-8869(01)00070-8

Document Version:

Publisher's PDF, also known as Version of record

\section{Please check the document version of this publication:}

- A submitted manuscript is the version of the article upon submission and before peer-review. There can be important differences between the submitted version and the official published version of record.

People interested in the research are advised to contact the author for the final version of the publication, or visit the DOI to the publisher's website.

- The final author version and the galley proof are versions of the publication after peer review.

- The final published version features the final layout of the paper including the volume, issue and page numbers.

Link to publication

\footnotetext{
General rights rights.

- You may freely distribute the URL identifying the publication in the public portal. please follow below link for the End User Agreement:

www.umlib.nl/taverne-license

Take down policy

If you believe that this document breaches copyright please contact us at:

repository@maastrichtuniversity.nl

providing details and we will investigate your claim.
}

Copyright and moral rights for the publications made accessible in the public portal are retained by the authors and/or other copyright owners and it is a condition of accessing publications that users recognise and abide by the legal requirements associated with these

- Users may download and print one copy of any publication from the public portal for the purpose of private study or research.

- You may not further distribute the material or use it for any profit-making activity or commercial gain

If the publication is distributed under the terms of Article $25 \mathrm{fa}$ of the Dutch Copyright Act, indicated by the "Taverne" license above, 


\title{
Modeling the connection between self-reported trauma and dissociation in a student sample
}

\author{
Harald Merckelbach*, Robert Horselenberg, Henk Schmidt \\ Department of Experimental Psychology, Maastricht University, PO Box 616, \\ 6200 MD Maastricht, The Netherlands
}

Received 28 August 2000; received in revised form 8 February 2001; accepted 15 March 2001

\begin{abstract}
A sample of 109 undergraduate students completed the Dissociative Experiences Scale and self-report measures on absent-mindedness, fantasy proneness, and childhood trauma. As in previous studies, dissociative tendencies were strongly related to absent-mindedness and fantasy proneness. Also, dissociative symptoms were linked to trauma self-reports. Structural equation modeling analyses showed that both the conventional trauma-dissociation model and an alternative dissociation-trauma model provided an adequate fit to our data. Thus, our results demonstrate that cross-sectional and non-clinical studies relying on self-reports of dissociation and trauma should seriously consider the possibility that dissociation, together with its correlates absent-mindedness and fantasy proneness, contribute to trauma self-reports. (C) 2002 Elsevier Science Ltd. All rights reserved,
\end{abstract}

Keywords: Dissociation; Fantasy proneness; Trauma; Structural equation modeling

Over the past decade, a large number of clinical as well as non-clinical studies have shown that dissociative experiences like depersonalization, derealization, amnesia, and identity disturbances, correlate with self-reports of traumatic childhood events (e.g. Chu \& Dill, 1990; Engel, Walker, \& Katon, 1996; Lange, De Beurs, Dolan, Lachnit, Sjollema, \& Hanewald, 1999; Nijman, Dautzenberg, Merckelbach, Jung, Wessel, \& Campo, 1999; Sandberg \& Lynn, 1992; Sanders \& Giolas, 1991; Saxe, Van der Kolk, Berkowitz, Chinman, Hall, Lieberg, \& Schwartz, 1993; Van den Hout, Merckelbach, \& Pool, 1996; Zlotnick, Shea, Pearlstein, Simpson, Costello, \& Begin, 1996). Many authors have taken this correlation to mean that dissociative experiences originate from adverse childhood events (e.g. sexual abuse, physical abuse, emotional neglect). According to this trauma-dissociation

\footnotetext{
* Corresponding author. Tel.: +31-43-3881945; fax: + 31-43-3881908.

E-mail address: h.merckelbach@psychology.unimaas.nl (H. Merckelbach).
} 
interpretation, dissociation can best be viewed as a long-term coping strategy that serves to compartmentalize overwhelming memories and emotions linked to childhood trauma (e.g. Classen, Koopman, \& Spiegel, 1993; Ross, 1997). Thus, this account is very clear about the causal direction that underlies the connection between self-reports of childhood trauma and adults' dissociative experiences in that it assumes that trauma functions as the primary antecedent of dissociative experiences (e.g. Gershuny \& Thayer, 1999; Putnam et al., 1996).

While the trauma-dissociation model provides a parsimonious and, therefore, attractive interpretation of the well-established link between self-reports of trauma and dissociation, it has not gone unchallenged (see for critical reviews, Frankel, 1990, 1996; Merckelbach \& Muris, 2001; Tillman, Nash, \& Lerner, 1994). To begin with, some studies have provided evidence that the link between childhood trauma and adult dissociative symptoms is considerably more complex than is often suggested in psychiatric literature. More specifically, these studies noted that the connection between concurrent self-reports of trauma and dissociation is, at least in part, mediated by respondents' current psychiatric complaints (Cima, Merckelbach, Klein, Shellbach-Matties, \& Kremer, 2001; Mulder, Beautrais, Joyce, \& Fergusson, 1998) and respondents' retrospectively perceived family environment (Nash, Hulsey, Sexton, Harralson, \& Lambert, 1993). A second, and probably more important point has to do with the commonly used instrument for measuring dissociative symptoms, namely the Dissociative Experiences Scale (DES; Bernstein \& Putnam, 1986). While the DES possesses good test-retest stability and internal consistency (see for a review, Van IJzendoorn \& Schuengel, 1996), we and others have consistently found that dissociative experiences tapped by the DES strongly overlap with fantasy proneness (Merckelbach, Muris, \& Rassin, 1999; Merckelbach, Rassin, \& Muris, 2000b; Rauschenberg \& Lynn, 1995; Silva \& Kirsch, 1992). As well, there are good reasons to believe that the DES is intimately linked to absent-mindedness as measured by the Cognitive Failures Questionnaire (CFQ; Broadbent, Cooper, Fitzgerald, \& Parkes, 1982; Merckelbach et al., 1999).

It is important to emphasize that both fantasy proneness and absent-mindedness are, in principle, benign characteristics that are not inherently psychopathological (e.g. Broadbent et al., 1982; Lynn \& Rhue, 1988). Meanwhile, it is conceivable that these two correlates of dissociation might compromise the accuracy of trauma self-reports. For example, people scoring high on fantasy proneness are more likely to develop pseudomemories (e.g. Hyman \& Billings, 1998) and to display overendorsement of items that sample autobiographical events (Merckelbach, Muris, Horselenberg, \& Stougie, 2000). Likewise, individuals scoring high on the CFQ are relatively vulnerabie to suggestive post-hoc misinformation (Merckelbach, Muris, Rassin, \& Horselenberg, 2000), presumably because they have reduced confidence in their own memory capabilities that, in turn, increases their receptivity to misleading cues provided by others. Of course, it is possible that a history of aversive childhood events acts as the major developmental cause of dissociation, fantasy proneness, absent-mindedness, positive response tendencies, and suggestibility (e.g. Lawrence, Edwards, Barraclough, Church, \& Hetherington, 1995). However, another distinct possibility is that the elevated fantasy proneness and absent-mindedness implicated in high DES scores are conductive to self-reports of trauma (e.g. Merckelbach, Muris, Horselenberg, \& Stougie, 2000; Merkelbach, Muris Rassin, \& Horselenberg, 2000; Merckelbach \& Muris, 2001). The idea here is not so much that individuals scoring high on dissociation react with bizarre and wildly inaccurate responses to self-report instruments of childhood trauma; rather, it is assumed that these individuals may have a tendency to exaggerate negative childhood experiences. That 
this possibility must be accorded serious consideration is demonstrated by a study of Johnson, Edman, and Danko (1995) who found that high DES individuals report having experienced a higher frequency of trivial bad events (e.g. "I have been short changed in stores").

In psychology, retrospective self-reports of autobiographical events have a notoriously bad track record. For example, in their longitudinal study, Henry, Mofitt, Caspi, Langley, and Silva (1994) followed a large sample of children and, at several points in time, gathered objective information about e.g. family conflict, injuries, and attachment to parents. Then, at age 18, retrospective reports of the youths were obtained and these were compared with objective records. By and large, the level of agreement between these two sources was quite poor, which led the authors to conclude that "reliance on retrospective reports about psychosocial variables should be approached with caution" (Henry et al., 1994, p. 92). Likewise, in his thought-provoking review of this issue, Schwarz (1999, p. 100) noted that "retrospective behavioral reports are highly fallible and strongly affected by the specifics of the research instrument used."

It would require a large-scale, longitudinal study of the type conducted by Henry et al. (1994) to determine with a high degree of precision to what extent trauma contributes to dissociative tendencies and to what extent the reverse is true i.e. to what extent dissociation through its correlates of fantasy proneness and absent-mindedness affect self-reports of trauma. To the best of our knowledge, no such study has been reported in the literature. Indeed, with a few exceptions (e.g. Cardena \& Spiegel, 1993), evidence for the popular trauma-dissociation model comes from crosssectional research that relied on retrospective self-reports of trauma.

In the absence of longitudinal research, the second best alternative to shed some light on the causality issue is provided by structural equation modeling performed on cross-sectional data (e.g. Gershuny \& Thayer, 1999; Schumacker \& Lomax, 1996). Basically, this approach combines several statistical techniques (e.g. path analysis) to examine how well an empirically derived correlational matrix fits with a particular causal model (e.g. Lawrence et al., 1995). Structural equation modeling yields a number of goodness-of-fit statistics (e.g. Chi square, Root Mean Square Error of Approximation). On the basis of these statistics, it is possible to determine to what extent a priori formulated causal models are consistent with observed data. Relying on a sample of undergraduate students, the current study used structural equation modeling to test two causal models about the link between self-reported trauma and dissociation (Fig. 1). The first model is the widely accepted trauma-dissociation model that holds that trauma precedes dissociation and its correlates, fantasy proneness and absent-mindedness. The second, and intuitively less obvious model, assumes that the correlates of dissociation heavily contribute to a positive endorsement strategy on self-report instruments of childhood trauma.

\section{Method}

\subsection{Participants}

There is no consensus about the minimum satisfactory sample size that is required for conducting structural equation modeling (Schumacker \& Lomax, 1996). Indeed, some authors (e.g. Lawrence et al., 1995) relied on sample sizes of less than 100, while other authors recommended sample sizes of 400 or more (Boomsma, 1982). In the absence of clear rules, we set our sample size 
on 30 participants per variable (see later). Of the 120 participants tested, 11 had missing values leaving 109 students ( $26 \mathrm{men}$ ) in the final sample. All participants volunteered to complete a set of questionnaires (see later) in return for a small financial compensation. Mean age of the sample was 19.5 years $($ S.D. $=2.3$ ).

\subsection{Procedure and questionnaires}

Participants were tested individually in a quiet lab chamber and completion of all questionnaires took about $45 \mathrm{~min}$. Order of questionnaires was counterbalanced across participants and a research assistant was always present to answer questions. Participants were assured that all information would be treated confidentially. Participants were given the following questionnaires.

\subsubsection{Dissociation experiences scale}

The Dissociative Experiences Scale (DES; Bernstein \& Putnam, 1986; Cronbach's alpha=0.92) is widely acknowledged as a standard instrument for measuring dissociative experiences. It comprises 28 items that assess the frequency of various dissociative phenomena in daily life. Examples of such phenomena include disturbances in memory, awareness, and identity. Participants indicate on $100-\mathrm{mm}$ visual analogue scales (anchors: $0=$ not at all; $100=$ very much) the percentage of time that they have experienced phenomena like talking out loud to oneself when one is alone or not recognizing friends or family members. Scores are averaged across items to obtain a mean
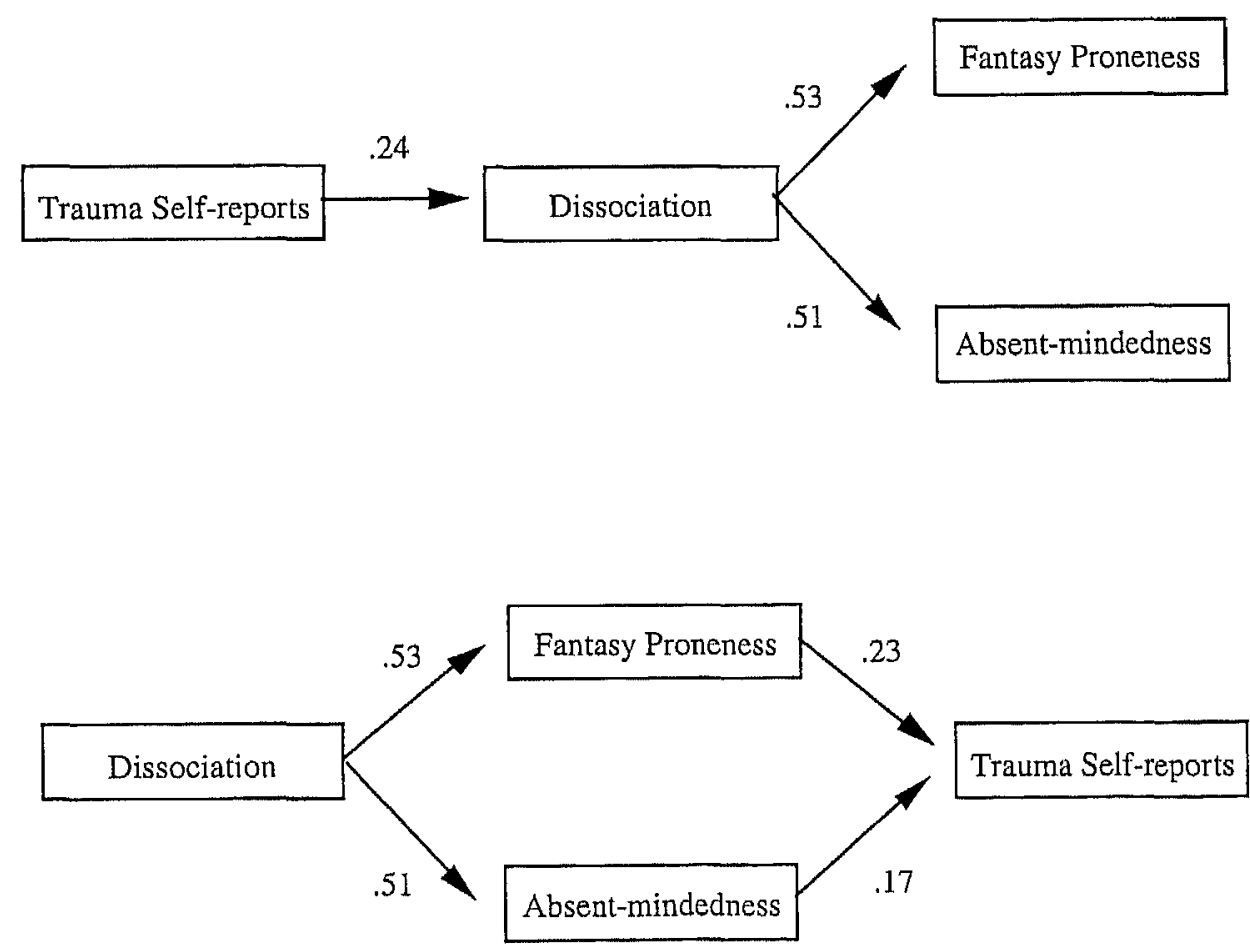

Fig. 1. Upper part: the Trauma-Dissociation Model (Model 1). Lower part: the Dissociation-Trauma Model (Model 2). Standardized regression weights are also shown and were derived from analyses on non-normalized data. 
DES score, with higher scores indicating a higher frequency of dissociative symptoms reported by the participant. Psychometric qualities of the DES are well established (Van IJzendoorn \& Schuengel, 1996).

\subsubsection{Creative experiences questionnaire}

The Creative Experiences Questionnaire (CEQ; Merckelbach, Horselenberg, \& Muris, 2001; Cronbach's alpha $=0.70$ ) is a Dutch instrument for measuring fantasy proneness. It comprises 25 dichotomous (yes/no) items that relate to daydreaming, intense fantasies, and imagination. CEQ items were derived from the extensive case descriptions of fantasy proneness provided by Wilson and Barber (1983). Typical examples are: "I spend more than half the day (daytime) fantasizing or daydreaming" and "Many of my fantasies are often just as lively as a good movie". The number of yes-answers is summed to yield a total CEQ score. Merckelbach, Horselenberg, and Muris (2001) summarize evidence that supports the reliability and validity of the CEQ. For example, Pearson product-moment correlations between CEQ, Tellegen's Absorption Scale (TAS; Roche \& McConkey, 1990) and the 44-item version of the Inventory of Childhood Memories and Imaginings (ICMI; Myers, 1983) exceed the 0.75 level.

\subsubsection{Cognitive Failures Questionnaire}

The Cognitive Failures Questionnaire (CFQ; Broadbent et al., 1982; Cronbach's alpha =0.83) is a self-report index of absent-mindedness. It lists 25 everyday slips, lapses, and minor blunders (e.g. "Do you forget appointments?"). Participants are asked to indicate how often they have experienced each cognitive failure in the past month. Responses are made on a 5-point scale (anchors: $0=$ never; $4=$ very often). Scores are summed to obtain a total CFQ score. Merckelbach, Muris, Nijman, and De Jong (1996) showed that the Dutch CFQ possesses adequate psychometric characteristics.

\subsubsection{Childhood Trauma Questionnaire}

The 25-item Short Form of the Childhood Trauma Questionnaire (CTQ; Bernstein \& Fink, 1998; Cronbach's alpha $=0.90$ ) comprises subscales that relate to emotional abuse (e.g. "When I was growing up, I thought that my parents wished I had never been born"), physical abuse (e.g. "When I was growing up, I believe that I was physically abused"), sexual abuse (e.g. "When I was growing up, someone tried to touch me in a sexual way, or tried to make me touch them"), emotional neglect (e.g. "When I was growing up, I felt loved"), and physical neglect (e.g. "When I was growing up, I didn't have enough to eat"). Each subscale contains five items that are answered on 5-point scales (anchors: $1=$ never true; $5=$ very often true). After reverse coding of some items, items can be summed to obtain a total CTQ score. Bernstein et al. (1994) showed that the full version of the CTQ demonstrates good test-retest stability, high internal consistency, and adequate correspondence with concurrent measures of self-reported trauma.

\subsection{Data analysis}

Pearson product-moment correlations between the pertinent measures were calculated. Together with standard deviations, correlations served as the input for structural equation modeling, which was carried out with EQS (Bentler, 1989). Given the relatively small sample size, we decided 
to obtain several fit-indices. Thus, for both models, the following fit-indices are reported (for a detailed discussion of these statistics, see Schumacker \& Lomax, 1996): (1) the Chi square Goodness-of-Fit value that has to be non-significant for the tested model to be considered a good fit with the observed correlational data; (2) the average off diagonal absolute standardized residuals (AASRs) that reflect the amount of unexplained variance under a specified model. AASRs should not exceed the value of 0.05 ; (3) the Comparative Fit Index (CFI) which compares the fit of a specified model with a hypothetical model in which none of the variables are correlated (a CFI of 0.90 or higher indicates that the tested model fits the data well); (4) the root mean square error of approximation (RMSEA) that is relatively insensitive to sample size and indicates the fit of the model in relation to the degrees of freedom. RMSEA values below 0.05 imply a close fit of the model and according to Browne and Cudeck (1993, p. 144) this .05 criterion is "no less subjective than the choice of $5 \%$ as a significance level"; and 5. the Bentler-Bonett non-normed fit index (NNFI) that according to some authors (e.g. Lawrence et al., 1995) provides a particularly good estimate of how well a model fits when data are based on small sample sizes. NNFI values that exceed the 0.9 level are indicative of well-fitting models.

\section{Results}

Table 1 shows descriptive statistics of the measures. Mean scores on dissociation (DES), absentmindedness (CFQ), and fantasy proneness (CEQ) are in close agreement with results obtained in previous non-clinical studies (e.g. Van IJzendoorn \& Schuengel, 1996; Broadbent et al., 1982, and Merckelbach, Horselenberg, \& Muris, 2001, respectively). As to the mean score on the trauma scale (CTQ), direct comparisons are difficult because normative scores for the Short Form of the CTQ have not yet been reported in literature. However, in terms of mean item scores, our results come close to those reported by Irwin (1998) who administered the full CTQ to a non-clinical sample.

Table 2 present Pearson product-moment correlations between DES, CFQ, CEQ, and CTQ. As can be seen, all inter-correlations attained significance, with those between dissociation, on the one hand, and absent-mindedness and fantasy proneness, on the other hand, being the most substantial ones (i.e. $r s>0.50$ ).

The upper part of Table 3 shows fit-indices for the two models specified in Fig. 1. Chi squares remained non-significant, indicating that the causal relations specified by both models were consistent with the observed data. The same is true for AASRs. Although both models had values

Table 1

Means, standard deviations, range, and skewness on dissociation (DES), Absent-Mindedness (CFQ), Fantasy Proneness (CEQ), and Self-Reported Childhood Trauma (CTQ) $(n=109)$

\begin{tabular}{lrrrr}
\hline Measure & Mean & S.D. & Range & Skewness \\
\hline DES & 17.1 & 10.6 & $2-49$ & 0.94 \\
CFQ & 42.6 & 10.8 & $18-67$ & -0.30 \\
CEQ & 7.4 & 3.6 & $1-20$ & 0.85 \\
CTQ & 36.8 & 7.4 & $25-76$ & 3.12 \\
\hline
\end{tabular}


well below the required 0.05 level, the conventional trauma-dissociation model appeared to have more unexplained variance than the dissociation-trauma model. Both models had good CFI's (i.e. >0.90), implying that the trauma-dissociation model as well as the dissociation traumamodel outperformed a null (i.e. unrestricted) model. However, RMSEA statistics suggested that the observed data are better accounted for by the dissociation-trauma model (RMSEA <0.01) than by the traditional trauma-dissociation model (RMSEA $=0.09$ ). For both models, NNFI values indicated good fitting.

The distribution of CTQ, CEQ, and DES scores was skewed and this may have affected the results of our structural equation modeling since this type of analysis assumes normal distributions. With this in mind, a second series of analyses was run, this time on normalized data. To this end, all questionnaire scores were subjected to $z$-transformations and in this way new correlations (Table 2) and standard deviations were obtained. These data served as the input for the second series of structural equation modeling analyses, the results of which are shown in the lower part of Table 3. Basically, they confirm the findings obtained with the first series of analyses in that support was found for both models. Note, however, that for the traditional trauma-dissociation model, several goodness-of-fit parameters indicated only moderate fit (i.e. Chisquare $=7.7, P=0.05 ;$ RSMEA $=0.12$ and $\mathrm{NNFI}=0.88$ ).

Table 2

Pearson Correlations between Dissociation (DES), Absent-Mindedness (CFQ), Fantasy Proneness (CEQ), and SelfReported Childhood Trauma (CTQ) $(n=109)^{\mathrm{a}}$

\begin{tabular}{lccr}
\hline & DES & CFQ & CEQ \\
\hline CFQ & $0.51^{* *}$ & & \\
CEQ & $\left(0.52^{* *}\right)$ & & \\
& $0.53^{* *}$ & $0.27^{* *}$ & \\
CTQ & $\left(0.50^{* *}\right)$ & $\left.0.25^{* *}\right)$ & $0.28^{* *}$ \\
& $0.24^{* *}$ & $\left(0.29^{* *}\right)$ & $\left(0.35^{* *}\right)$ \\
\hline
\end{tabular}

a Correlations between parentheses are based on normalized data.

$*^{*} P<0.01$, (one-tailed).

Table 3

Fit-indices of the conventional trauma-dissociation model (model 1) and the alternative dissociation-trauma model (modeI 2) for non-normalized (upper part) and normalized (lower part) data (see also Fig. 1) a

\begin{tabular}{lllllll}
\hline & Chi square (d.f.) & $P$ & AASR & CFI & RMSEA & NNFI \\
\hline Model 1 & $5.62(3)$ & 0.13 & 0.044 & 0.96 & 0.09 & 0.93 \\
Model 2 & $0.19(2)$ & 0.91 & 0.005 & 1.00 & 0.00 & 1.07 \\
Model 1 & $7.7(3)$ & 0.05 & 0.029 & 0.94 & 0.12 & 0.88 \\
Model 2 & $1.5(2)$ & 0.47 & 0.009 & 1.00 & 0.00 & 1.02 \\
\hline
\end{tabular}

a AASR, average off-diagonal absolute standardized residuals; CFI, Comparative Fit Index; RMSEA, root mean square error of approximation; NNFI, Bentler-Bonett non-normed fit index.

b Normalized data. 
The trauma-dissociation model specified in Fig. 1 is only one possible version of models that order trauma before dissociation. More specifically, it is a version that assumes that the connection between trauma, on the one hand, and fantasy proneness and absent-mindedness, on the other hand, is fully mediated by dissociation. Other causal orderings in which trauma precedes dissociation are conceivable. However, highly similar results were obtained when other versions of the trauma-dissociation model were subjected to structural equation modeling. For example, testing a model in which trauma directly affects both dissociation and absent-mindedness, while dissociation directly affects fantasy proneness yielded a RMSEA value of 0.09 .

\section{Discussion}

The results of the present study can be summarized as follows. To begin with, the current study replicates previous findings (e.g. Merckelbach et al., 1999; Merckelberg, Muris, Horselenberg, \& Stougie, 2000; Merckelberg, Rassin, \& Muris, 2000; Merckelberg, Muris, Rassin, \& Horselenberg, 2000; Rauschenberger \& Lynn, 1995; Silva \& Kirsch, 1992) in that robust correlations were found between dissociative tendencies as measured by DES and absent-mindedness and fantasy-proneness as indexed by CFQ and CEQ, respectively. Secondly, like previous non-clinical studies, DES scores were positively correlated with self-reports of trauma (e.g. Sandberg \& Lynn, 1992; Van den Hout et al., 1996). Thirdly, structural equation modeling analyses showed that the data gathered in our non-clinical sample provide a degree of support to both the traditional trauma-dissociation and the intuitively less obvious dissociation-trauma model. One could even argue that our data are in some respects better described by the latter model (i.e. dissociation and its correlates serve as antecedents of trauma self-reports) than by the former model (i.e. trauma self-reports function as antecedents of dissociation and its correlates). More precisely, for nonnormalized data, the RMSEA value of the conventional trauma-dissociation model fell short of the recommended .05 criterion (e.g. Browne \& Cudeck, 1993). For normalized data, the Chisquare for the trauma-dissociation model approached significance. As well, both RMSEA and NNFI parameters for these data suggested reasonable error in the extent to which the traditional trauma-dissociation model approximated the data. Meanwhile, it should be acknowledged that the precise choice and interpretations of goodness-of-fit criteria is a much-debated issue (e.g. Schumacker \& Lomax, 1996). Therefore, the safest conclusion that can be drawn from our data is that the intuitively less obvious dissociation-trauma model proved to be consistent with the observed data.

Limitations of the present study include its cross-sectional design and its heavy reliance on selfreports of a non-clinical sample. Note that with such a sample, one expects relatively low rates of childhood trauma. Admittedly, the restriction of range that this implies may have contributed to the equivalence of the various causal models tested. Another limitation has to do with the fact that there is no precise psychometric information available for the Short Form of the CTQ. Thus, it may well be the case that a longitudinal study based on objective records of childhood traumas and a mixed sample would favor an entirely different model, for example a model in which objective reports of trauma do serve as the primary cause of dissociation and its correlates (but see Cima et al., 2001; Sanders \& Giolas, 1991). With these restrictions in mind, the current results add further weight to studies that have questioned the notion that dissociative tendencies are a 
straightforward consequence of childhood trauma (e.g. Frankel, 1990, 1996; Mulder et al., 1998; Tillman et al., 1994; Yehuda et al., 1996). Although the trauma-dissociation model has become popular in the psychiatric literature, it is also to a large extent based on cross-sectional designs that include retrospective self-reports of childhood trauma in non-clinical samples (see for a review, Merckelbach \& Muris, 2001). At the very least, our results indicate that with such data, one should seriously consider the possibility that causal directions may also flow from dissociation to trauma self-reports.

We certainly do not want to suggest that our results demonstrate that relatively high levels of absent-mindedness or fantasy proneness elicit wildly inaccurate responses on self-report measures of trauma. The processes implicated by our dissociation-trauma model are probably more complex and subtle. Consider the self-report measure of childhood trauma used in the current study. The CTQ consists of some fairly specific items (e.g. "when I was growing up, I got hit or beaten so badly that it was noticed by someone like a teacher, neighbor, or doctor"), but it also includes broadly formulated items (e.g. "When I was growing up, someone molested me"). Both categories of items are scored on a Likert frequency scale that ranges from "never true" to "very often true". Schwarz (1999) pointed out that broadly formulated items require disambiguation, and one way in which respondents accomplish this is by using the information that is provided by quantifiers such as "very often". In his words, "the same expression denotes different frequencies in different domains. Thus, frequently suffering from headaches reflects higher absolute frequencies that frequently suffering from heart attacks" (Schwarz, 1999; p. 99). Germane to this issue is a recent study by Lipschitz, Bernstein, Winegar, and Southwick (1999; p. 650) showing that the CTQ has a relatively low threshold for detecting sexual abuse, presumably because it relies on a "Likert-type format that might facilitate the reporting of events that were infrequent or less subjectively distressing." Perhaps, then, benign traits like fantasy proneness promote an overinclusive disambiguation of vague trauma items and this might explain why dissociation through its correlates contributes to trauma self-reports. Note that this line of reasoning assumes that people high on dissociation and its correlates did experience aversive childhood events (e.g. Johnson et al., 1995) and although these events may not necessarily have a traumatic quality, they may, of course, have contributed to the dissociative symptoms. Clearly, studies examining how individuals high on dissociation disambiguate vague trauma items may shed light on this important issue.

\section{References}

Bentler, P. (1989). EQS structural relations program manual. Los Angeles CA: BMDP Statistical Software.

Bernstein, D. P., \& Fink, L. A. (1998). CTQ: Childhood Trauma Questionnaire: a retrospective self-report. San Antonio T: Psychological Corporation.

Bernstein, D. P., Fink, L., Handelsman, L., Foote, J., Lovejoy, M., Wenzel, K., Saparetor, E., \& Ruggiero, J. (1994). Initial reliability and validity of a new retrospective measure of child abuse and neglect. American Journal of Psychiatry, 151, 1132-1136.

Bernstein, E. M., \& Putnam, F. W. (1986). Development, reliability, and validity of a dissociation scale. Journal of Nervous and Mental Disease, 174, 727-735.

Boomsma, A. (1982). The robustness of LISREL against small sample size and nonnormality. Amsterdam: Sociometric Research Foundation.

Broadbent, D. E., Cooper, P. F., Fitzgerald, P., \& Parkes, L. R. (1982). The Cognitive Failures Questionnaire (CFQ) and its correlates. British Journal of Clinical Psychology, 21, 1-16. 
Browne, M. W., \& Cudeck, R. (1993). Alternative ways of assessing model fit. In K. A. Bollen, \& J. Scott Long (Eds.), Testing structural equation models (pp. 136-162). Newbury Park: Sage.

Cardena, E., \& Spiegel, D. (1993). Dissociative reactions to the San Francisco Bay Area earthquake of 1989. American Journal of Psychiatry, 150, 474-478.

Chu, J. A., \& Dill, D. L. (1990). Dissociative symptoms in relation to childhood physical and sexual abuse. American Journal of Psychiatry, 147, 887-892.

Cima, M., Merckelbach, H., Klcin, B., Shellbach-Matties, R., \& Kremer, K. (2001). Frontal lobe dysfunctions, dissociation, and trauma self-reports in forensic psychiatric patients. Journal of Nervous and Mental Disease, 189, $188-190$.

Classen, C., Koopman, C., \& Spiegel, D. (1993). Trauma and dissociation. Bulletin of the Menninger Clinic, 27, $178-194$.

Engel, C. C., Walker, E. A., \& Katon, W. J. (1996). Factors related to dissociation among patients with gastrointestinal complaints. Journal of Psychosomatic Research, 40, 643-653.

Frankel, F. H. (1990). Hypnotizability and dissociation. American Journal of Psychiatry, 147, 823-829.

Frankel, F. H. (1996). Dissociation: the clinical realities. American Journal of Psychiatry (Festschrift Supplement), 153, 64-70.

Gershuny, B. S., \& Thayer, J. F. (1999). Relations among psychological trauma, dissociative phenomena, and traumarelated distress: areview and integration. Clinical Psychology Review, 19, 631-657.

Henry, B., Moffitt, Caspi, A., Langley, J., \& Silva, P. A. (1994). On the remembrance of things past: A longitudinal evaluation of the retrospective method. Psychological Assessment, 6, 92-101.

Hyman, I. E., \& Billings, F. J. (1998). Individual differences and the creation of false memories. Memory, 6, 1-20.

Irwin, H. J. (1998). Dissociative tendencies and the sitting duck: are self-reports of dissociation and victimization symptomatic of neuroticism? Journal of Clinical Psychology, 54, 1005-1015.

Johnson, R. C., Edman, J. L., \& Danko, G. P. (1995). Self reported negative experiences and dissociation. Personality and Individual Differences, 18, 793-795.

Lange, A., De Beurs, E., Dolan, C., Lachnit, T., Sjollema, S., \& Hanewald, G. (1999). Long-term effects of childhood sexual abuse: objective and subjective characteristics of the abuse and psychopathology in later life. Journal of Nervous and Mental Disease, 187, 150-158.

Lawrence, T., Edwards, C., Barraclough, N., Church, S., \& Hetherington, F. (1995). Modelling childhood causes of paranormal belief and experience: childhood trauma and childhood fantasy. Personality and Individual Differences, 19, 209-215.

Lipschitz, D. S., Bernstein, D. P., Winegar, R. K., \& Southwick, S. M. (1999). Hospitalized adolescents' reports of sexual and physical abuse: a comparison of two self-report measures. Journal of Traumatic Stress, 12, 641-654.

Lynn, S. J., \& Rhue, J. W. (1988). Fantasy proneness: hypnosis, developmental antecedents, and psychopathology. American Psychologist, 43, 350-54.

Merckelbach, H., \& Muris, P. (2001). The causal link between self-reported trauma and dissociation: a critical review. Behaviour Research and Therapy, 39, 245-254.

Merckelbach, H., Muris, P., Horselenberg, R., \& Stougie, S. (2000). Dissociation, reality monitoring, and response bias. Personality and Individual Differences, 28, 49-58.

Merckelbach, H., Muris, P., Nijman, H., \& De Jong, P. J. (1996). Self-reported cognitive failures and neurotic symptomatology. Personality and Individual Differences, 20, 715-724.

Merckelbach, H., Muris, P., \& Rassin, E. (1999). Fantasy proneness and cognitive failures as correlates of dissociative experiences. Personality and Individual Differences, 26, 961-967.

Merckelbach, H., Horselenberg, R., \& Muris, P. (2001) The Creative Experiences Questionnaire (CEQ): a brief selfreport measure of fantasy proneness. Personality and Individual Differences (in press).

Merckelbach, H., Rassin, E., \& Muris, P. (2000). Dissociation, schizotypy, and fantasy proneness in undergraduate students. Journal of Nervous and Mental Disease, 188, 428-431.

Merckelbach, H., Muris, P., Rassin, E., \& Horselenberg, R. (2000). Dissociative experiences and interrogative suggestibility in college students. Personality and Individual Differences, 29, 1133-1140.

Mulder, R. T., Beautrais, A. L., Joyce, P. R., \& Fergusson, D. M. (1998). Relationship between dissociation, childhood sexual abuse, childhood physical abuse, and mental illness in a general population sample. American Journal of Psychiatry, 155, 806-811.

Myers, S. A. (1983). The Wilson-Barber Inventory of Childhood Memories and Imaginings: children's form and norms for 1337 children and adolescents. Journal of Mental Imagery, 7, 83-94. 
Nash, M. R., Hulsey, T. L., Sexton, M. C., Harralson, T. L., \& Lambert, W. (1993). Long-term sequelae of childhood sexual abuse: perceived family environment, psychopathology, and dissociation. Journal of Consulting and Clinical Psychology, 61, 276-283.

Nijman, H., Dautzenberg, M., Merckelbach, H., Jung, P., Wessel, I., \& Campo, J. (1999). Self-mutilating behavior of psychiatric inpatients. European Psychiatry, 14, 4-10.

Putnam, F. W., Carlson, E. B., Ross, C. A., Anderson, G, Clark, P., Torem, M., Bowman, E. S., Coons, Ph., Chu, J. A., Dill, D. L., Loewenstein, R. J., \& Braun, B. G. (1996). Patterns of dissociation in clinical and nonclinical samples. Journal of Nervous and Mental Disease, 184, 673-679.

Rauschenberg, S. L., \& Lynn, S. J. (1995). Fantasy proneness, DSM-III-r axis I psychopathology, and dissociation. Journal of Abnormal Psychology, 104, 373-380.

Roche, S. M., \& McConkey, K. M. (1990). Absorption: nature, assessment, and correlates. Journal of Personality and Social Psychology, 59, 91-101.

Ross, C. A. (1997). Dissociative identity disorder: diagnosis, clinical features, and treatment of multiple personality. New York: Wiley.

Sandberg, D. A., \& Lynn, S. J. (1992). Dissociative experiences, psychopathology and adjustment, and child and adolescent maltreatment in female college students. Journal of Abnormal Psychology, 101, 717-723.

Sanders, B., \& Giolas, M. H. (1991). Dissociation and childhood trauma in psychologically disturbed adolescents. American Journal of Psychiatry, 148, 50-54.

Saxe, G. N., Van der Kolk, B. A., Berkowitz, M. D., Chinman, G., Hall, K., Lieberg, G., \& Schwartz, J. (1993). Dissociative disorders in psychiatric inpatients. American Journal of Psychiatry, 150, 1037-1042.

Schumacker, R. E., \& Lomax, R. G. (1996). A beginner's guide to structural equation modeling. Mahwah NJ: Erlbaum.

Schwarz, N. (1999). Self-reports: how the questions shape the answers. American Psychologist, 54, 93-105.

Silva, C. E., \& Kirsch, I. (1992). Interpretive sets, expectancy, fantasy proneness, and dissociation as predictors of hypnotic response. Journal of Personality and Social Psychology, 63, 847-856.

Tillman, J. G., Nash, M. R., \& Lerner, P. M. (1994). Does trauma cause dissociative psychopathology?. In S. J. Lynn, \& J. W. Rhue (Eds.), Dissociation: clinical and theoretical perspectives (pp. 395-413). New York: Guilford.

Van den Hout, M. A., Merckelbach, H., \& Pool, K. (1996). Dissociation, reality monitoring, trauma, and thought suppression Behavioural and Cognitive Psychotherapy, 24, 97-108.

Van IJzendoorn, M. H., \& Schuengel, C. (1996). The measurement of dissociation in normal and clinical populations: meta-analytic validation of the Dissociative Experiences Scale (DES). Clinical Psychology Review, 16, 365-382.

Wilson, S. C., \& Barber, T. X. (1983). Fantasy-prone personality: implications for understanding imagery, hypnosis, and parapsychological phenomena. In A. A. Sheikh (Ed.), Imagery: current theory, research, and application (pp. 340387). New York: Wiley.

Yehuda, R., Elkin, A., Binder-Brynes, K., Kahana, B., Southwick, S. M., Schmeidler, J., \& Giller, E. L. (1996). Dissociation in aging Holocaust survivors. American Journal of Psychiatry, 153, 935-940.

Zlotnick, C., Shea, M. T., Pearlstein, T., Simpson, E., Costello, E., \& Begin, A. (1996). The relationship between dissociative symptoms, alexithymia, impulsivity, sexual abuse, and self-mutilation. Comprehensive Psychiatry, 37, 12-16. 